\title{
Physicochemical and Photocatalytic Properties of Fe- Pillared Bentonite at Various Fe Content
}

\author{
Is Fatimah*, Yuyun Yunani Nurkholifah \\ Chemistry Department, Islamic University of Indonesia, Kampus Terpadu UII, \\ Jl. Kaliurang Km 14, Sleman, Yogyakarta, Indonesia
}

Received: 29th March 2016; Revised: 30th August 2016; Accepted: 1 ${ }^{\text {st }}$ September 2016

\begin{abstract}
Iron-pillared bentonites (Fe/Bents) were successfully prepared using a ferric chloride precursor. The prepared samples were characterized using XRD, BET and SEM-EDX. The results show that the pillared bentonite physicochemical character is affected by the iron content in a precursor solution. By $\mathrm{Fe}$ content variation, it is found that $\mathrm{Fe}$ content in $\mathrm{Fe} / \mathrm{Bents}$ is not linearly correlated with the specific surface area and the increased in d001 in which both the maximum specific surface are and d001 reach maximum at the $\mathrm{Fe}$ content of $20 \mathrm{mmol} / \mathrm{g}$. Due to the kinetics of photocatalytic activity in phenol removal, it is concluded that in photo-Fenton-like processes. Copyright (C) 2016 BCREC GROUP. All rights reserved
\end{abstract}

Keywords: Bentonite; Photocatalysis; Photo-Fenton like process; Pillared clays

How to Cite: Fatimah, I., Nurkholifah, Y.Y. (2016). Physicochemical and Photocatalytic Properties of Fe-Pillared Bentonite at Various Fe Content. Bulletin of Chemical Reaction Engineering \& Catalysis, 11 (3): 398-405 (doi:10.9767/bcrec.11.3.456.398-405)

Permalink/DOI: http://doi.org/10.9767/bcrec.11.3.456.398-405

\section{Introduction}

Advanced oxidation processes (AOPs) are one of the most important technologies for clean and green technology aimed towards toxic and organic contamination in water. These processes are efficient because they exploits the high reactivity of $\mathrm{HO}$ radicals for fast mineralization of even less reactive pollutants [1]. Thus, the presence of a photocatalyst with oxidants in the contaminated solution plays an important role in activating the radicals. Several heterogeneous photocatalysts for AOPs have been reported; among the photocatalysts, the combination of $\mathrm{Fe}(\mathrm{II})$ and/or $\mathrm{Fe}$ (III) with $\mathrm{H}_{2} \mathrm{O}_{2}$ under ultraviolet and/or visible light have been exten-

* Corresponding Author.

E-mail: isfatimah@uii.ac.id (I. Fatimah) sively reported as Fenton and Fenton-like processes, respectively [2-4]. Many studies have used advanced oxidation processes involving Fenton and Fenton-like components for industrial and pharmaceutical organic compounds (5-10). However, using a photocatalyst in bulk form is problematic because slurry photocatalysis requires a post-treatment recovery step. An additional problem with its use in pure form is the potential for rapidly reducing photoactivity. Immobilizing a semiconductor photocatalyst in a solid support with a high specific surface area and chemical stability is one strategy for enhancing performance. Among the solid supports that can be used, clay is a potential inorganic support. Many studies have attempted to immobilize $\mathrm{TiO}_{2}, \mathrm{ZnO}$ and $\mathrm{ZrO}_{2}$ photocatalysts in a clay matrix, particularly the smectite class of clay and $\mathrm{Fe}$ (II) and Fe(III) photocatalysts [11- 
13]. The interlayer region of the smectite clay structure can be modified with metal and metal oxide using a pillarization procedure [14].

Iron(III) is a cheap Fenton catalyst and has been reported in certain investigations. Because $\mathrm{Fe}(\mathrm{III})$ plays a role in the photocatalytic mechanism, which involves light, it is referred to as a photo-Fenton-like process. In the AOP mechanism, the reduction-oxidation reactions between $\mathrm{Fe}(\mathrm{II}) / \mathrm{Fe}(\mathrm{III})$ occur in the presence of hydrogen peroxide. Hydrogen peroxide is an oxidant that promotes formation of reactive components, such as $(\cdot \mathrm{OH})$ and hydroperoxyl $(\cdot \mathrm{OOH})$ radicals. The radicals formed from hydrogen peroxide decomposition can oxidize organic compounds adsorbed over the catalyst or degrade soluble organic compounds proximal to active iron ions $[8,9]$.

The $\mathrm{Fe}(\mathrm{III}) / \mathrm{Fe}$ (II) complexes were stabilized through immobilization in a pillared clay form. The $\mathrm{Fe}(\mathrm{III}) / \mathrm{Fe}$ (II) complexes formed on the surface of a support can react with $\mathrm{H}_{2} \mathrm{O}_{2}$, which facilitates iron ion participation in the Fenton catalytic cycle. Considering the abundance of natural bentonite in Indonesia, natural bentonite is used as a raw material. The Fe(III)pillared bentonite (henceforth referred to as Fe/Bent) was proposed as a cheap and reusable photocatalyst. Previous studies have reported the success of Fe-pillaring smectite clay alone and combined with $\mathrm{Al}$ pillaring for photocatalysis applications [11,15-17]. Certain investigations have reported the effectiveness of pillaring $\mathrm{Fe}$ at enhancing photoactivity. Aim of this research is to study the advancing effect of $\mathrm{Fe}$ content in $\mathrm{Fe} / \mathrm{Bents}$ to the physicochemical character and photoactivity. The physicochemical character of the materials can be identified from the specific surface area as well as crystallinity and for a photocatalytic activity test, phenol degradation was used as the reaction model.

\section{Materials and Methods}

\subsection{Materials}

Phenol and hydrogen peroxide $(30 \%, \mathrm{w} / \mathrm{w})$ was purchased from Sigma-Aldrich (M) Sdn. Bhd. The ferric chloride $\left(\mathrm{FeCl}_{3}\right)$ and $\mathrm{H}_{2} \mathrm{SO}_{4}$ were obtained from Merck, Germany. Natural bentonite was obtained from Pacitan, East Java, Indonesia and was used as a raw material. All chemicals used were analytical grade without further purification. However, for natural bentonite, acid activation was performed through refluxing bentonite in $0.2 \mathrm{M}$ $\mathrm{H}_{2} \mathrm{SO}_{4}$ for $6 \mathrm{~h}$ followed by washing, neutralization, drying and grinding before use.
Some distilled water was used throughout the study.

\subsection{Method}

A bentonite was pillarized by first preparing a $\mathrm{Fe}(\mathrm{III})$ precursor through diluting $\mathrm{FeCl}_{3}$ and $\mathrm{NaOH}$ at the molar ratio ${ }^{-} \mathrm{OH} / \mathrm{Fe}=1: 1$ in water followed by stirring overnight. The precursor was dispersed into a bentonite suspension in water $(5 \mathrm{wt} \%$.) and was stirred at room temperature overnight. The theoretical $\mathrm{Fe}$ content in the dispersion was varied at the molar ratios of $5,10,20,40$, and $60 \mathrm{mmol} / \mathrm{g}$. The mixture was filtered and washed with water until the filtrate was free from $\mathrm{Cl}^{-}$. The solid obtained from the filtration and neutralization was dried before calcination at $400{ }^{\circ} \mathrm{C}$ for $4 \mathrm{~h}$ under air flow. The materials produced by these steps are referred to as Fe/Bent-5, Fe/Bent-10, Fe/Bent-20, Fe/Bent-40 and $\mathrm{Fe} / \mathrm{Bent}-60$, respectively, for the various $\mathrm{Fe}$ levels.

An X-ray diffraction (XRD) analysis was performed to confirm successful pillarization by estimating the do01 change in the bentonite structure. A Shimadzu XRD X6000 equipped for $\mathrm{Ni}$-filtered $\mathrm{Cu}-\mathrm{Ka}$ measurements was used for measurements in the $2 \theta$ range of $3-75^{\circ}$. The material surface profiles were studied using the gas sorption analyzer NOVA 1200e. The specific surface area (SSA) was estimated using the Brunauer-Emmett-Teller (BET) method. To measure $\mathrm{Fe}$ and other main elements in the pillared bentonites and also to get surface profile, scanning electron microscope-energy dispersive X-ray (SEM-EDX) spectroscopy from JEOL was used.

The photocatalytic activity of the materials was tested for phenol removal. Four methods, adsorption, photocatalysis, Fenton and photoFenton-like processes, were examined. The adsorption processes included adding a catalyst powder without UV light exposure and without $\mathrm{H}_{2} \mathrm{O}_{2}$ addition, while the photocatalytic processes included a reaction system with catalyst powder added in the presence of UV light and without $\mathrm{H}_{2} \mathrm{O}_{2}$. Fenton process and the photo-Fenton-like processes included adding a catalyst with $\mathrm{H}_{2} \mathrm{O}_{2}$ and both $\mathrm{UV}$ and $\mathrm{H}_{2} \mathrm{O}_{2}$ respectively. To control for the process, a photolysis system was constructed that only included UV and $\mathrm{H}_{2} \mathrm{O}_{2}$ without a catalyst. A batch photoreactor consisting of a thermocontrolled beaker glass was placed $20 \mathrm{~cm}$ under a UV B lamp Philips $40 \mathrm{~W}$ for each test. Catalyst powder composed of $0.2 \mathrm{~g}$ was mixed into a test solution (phenol $20 \mathrm{ppm}, 500 \mathrm{~mL}$ ) 
and illuminated by UV light under stirring; the samples were obtained at certain times: 15,30 , $45,60,120$, and $240 \mathrm{~min}$. For the photo-Fentonlike process, $\mathrm{H}_{2} \mathrm{O}_{2}$ was added for the experiment until the molar ratio of phenol: $\mathrm{H} 2 \mathrm{O} 2$ was 10:1. The samples were taken sequentially at certain times from the treated solution using syringe and the phenol concentration was monitored using high performance liquid chromatography. A Perkin Elmer HPLC instrument was used.

\section{Results and Discussion}

\subsection{Material Characterization}

Successful pillarization was demonstrated based on the XRD pattern for bentonite d 001 before and after pillarization (Figure 1). From the XRD patterns it is seen that pillarization affect to increase do01 along increasing $\mathrm{Fe}$ content until $20 \mathrm{mmol} / \mathrm{g}$ but then after the addition to the value higher than $20 \mathrm{mmol} / \mathrm{g}$ the do01 getting lower. The Fe/Bent-10 showed an increase in do01 at approximately $1.88 \mathrm{~nm}$, which indicates that Fe pillars inserted into the bentonite interlayers. Further, as the $\mathrm{Fe}$ content increased during pillarization, Fe/Bent20 exhibited two peaks that correspond to the do01 values $2.02 \mathrm{~nm}$ and $0.22 \mathrm{~nm}$, and a new peak at $24.5^{\circ}$ reflects the presence of a $\alpha-\mathrm{Fe}_{2} \mathrm{O}_{3}$ phase, i.e., magnetite (JCPDS: 19-0629) [18]. The two peaks are likely related to the different iron oxide aggregates formed between the bentonite interlayers. However, at higher $\mathrm{Fe}$ levels, Fe/Bent-40 and Fe/Bent-60 showed a single d001 peak at $15.20 \mathrm{~nm}$ and $15.18 \mathrm{~nm}$ respectively, while an $\alpha-\mathrm{Fe}_{2} \mathrm{O}_{3}$ peak was not observed in both. The high $\mathrm{Fe}$ precursor concentration is likely due to ineffective $\mathrm{Fe}$ ion insertion during ion exchange. The presence of $\mathrm{Fe}$ in the pillared bentonites is also demonstrated by an increase in $\mathrm{Fe}$ content as the $\mathrm{Fe}$ content from a $\mathrm{Fe}$ precursor solution increases (Table 1). However the increasing $\mathrm{Fe}$ content in $\mathrm{Fe} /$ Bents is not linearly correlated with the $\mathrm{Fe}$ content in pillaring solution. This refers to the cation exchange in the pillaring process so the inserted $\mathrm{Fe}$ was directed by the equilibrium mechanism.

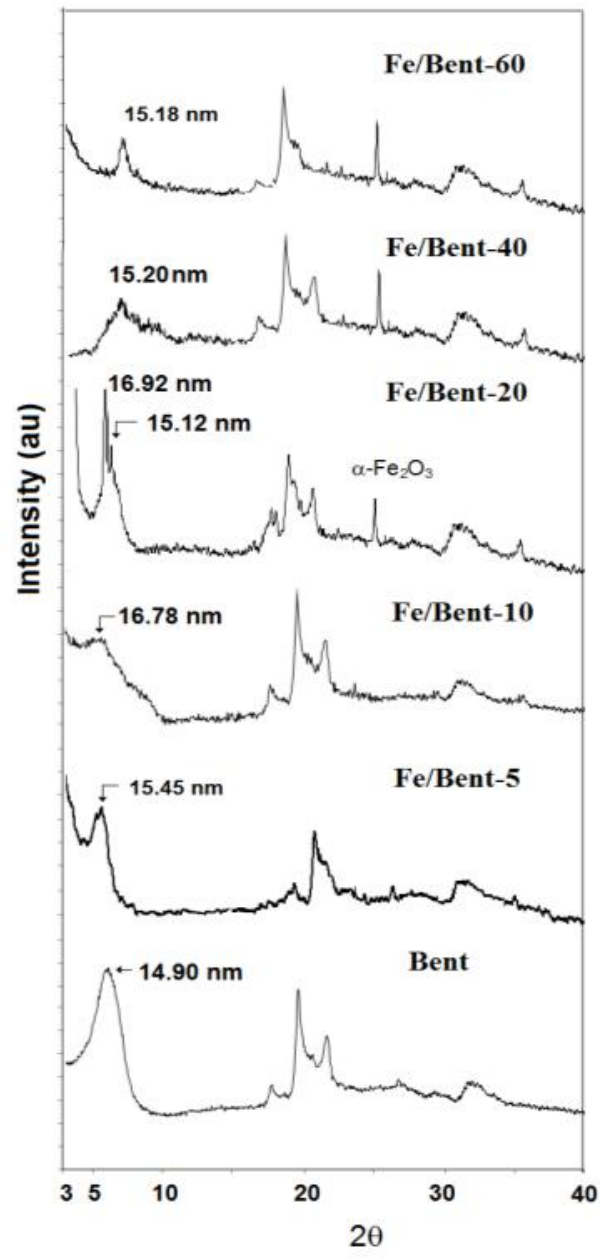

Table 1. Elemental analysis result of bentonite and pillared bentonites

\begin{tabular}{ccccccc}
\hline \multirow{2}{*}{$\begin{array}{c}\text { Component } \\
\text { (wt \%) }\end{array}$} & Bent & $\begin{array}{c}\text { Fe/Bent- } \\
5\end{array}$ & $\begin{array}{c}\text { Fe/Bent } \\
-10\end{array}$ & $\begin{array}{c}\mathrm{Fe} / \mathrm{Ben} \\
\mathrm{t}-20\end{array}$ & $\begin{array}{c}\mathrm{Fe} / \mathrm{Ben} \\
\mathrm{t}-40\end{array}$ & $\begin{array}{c}\text { Fe/Ben } \\
\mathrm{t}-60\end{array}$ \\
\cline { 2 - 6 } & 8.33 & 5.04 & 5.75 & 3.73 & 2.03 & 2.01 \\
$\mathrm{Na}{ }_{2} \mathrm{O}$ & 2.82 & 2.09 & 1.88 & 1.21 & 1.04 & 0.98 \\
$\mathrm{MgO}$ & 21.19 & 21.34 & 21.59 & 21.33 & 20.79 & 15.45 \\
$\mathrm{Al}_{2} \mathrm{O}_{3}$ & 59.8 & 58.9 & 58.97 & 56.08 & 55.02 & 46.04 \\
$\mathrm{SiO}_{2}$ & 3.83 & 11.76 & 9.75 & 15.84 & 19.34 & 34.6 \\
$\mathrm{FeO}$ & 0.77 & 0.11 & 0.12 & 0.09 & 0.02 & 0.01 \\
$\mathrm{CaO}$ & & & & & &
\end{tabular}

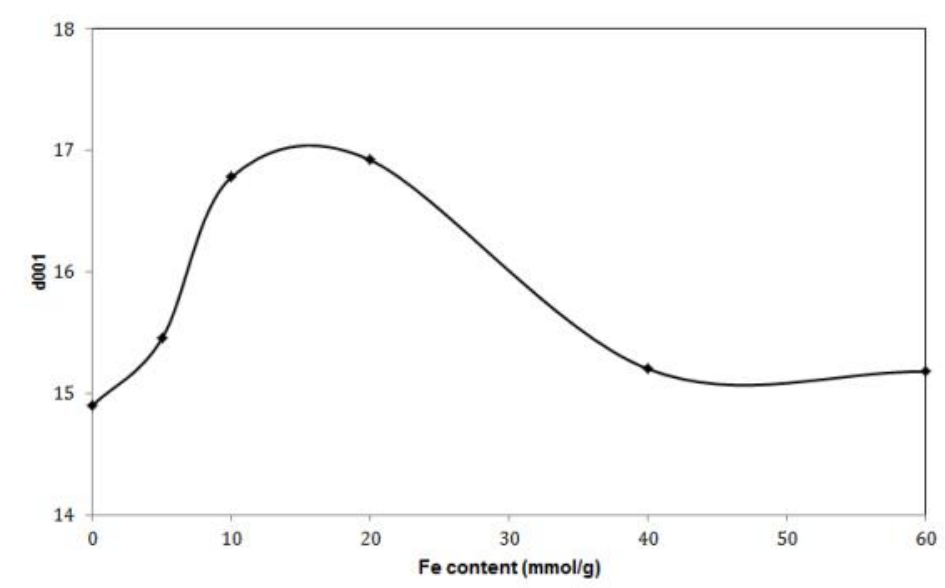

Figure 1. XRD patterns of materials 
Pillared bentonite nitrogen adsorptiondesorption patterns also differ from those of raw bentonite because a higher adsorption capacity was confirmed through the change in the pattern that reflects type IV based on IUPAC classification of adsorption-desorption isotherms. Both microporous and mesoporous structures were present in the pillared bentonite (Figure 2). The surface parameters consist of specific surface area, pores volume and pore radius, which are listed in Table 2 .

Consistent with the XRD pattern and the porous distribution, the modified bentonite exhibits a higher surface area, and Fe/Bent-20 generated the highest value. Higher Fe content
(Fe/Bent-40 and Fe/Bent-60) do not give the highest specific surface, which is related to the lowest do01 value, compared with Fe/Bent-40, while the Fe/bent-20 exhibited the greatest pore volume. The contrasting data suggest that Fe/Bent-40 and Fe/Bent-60 form a house of cards structure, which is also evidenced by the presence of a modal pore at the pore size distribution. Fe/Bent-40 pore distribution exhibits the modal pore at approximately $60 \AA$ instead of dominant pore sizes at approximately $25 \AA$ while Fe/Bent-60 exhibits the modal pore at around $32 \AA$ (Figure 3) [19,20]. The surface morphology of the materials also gives confirmation on the change of surface profile
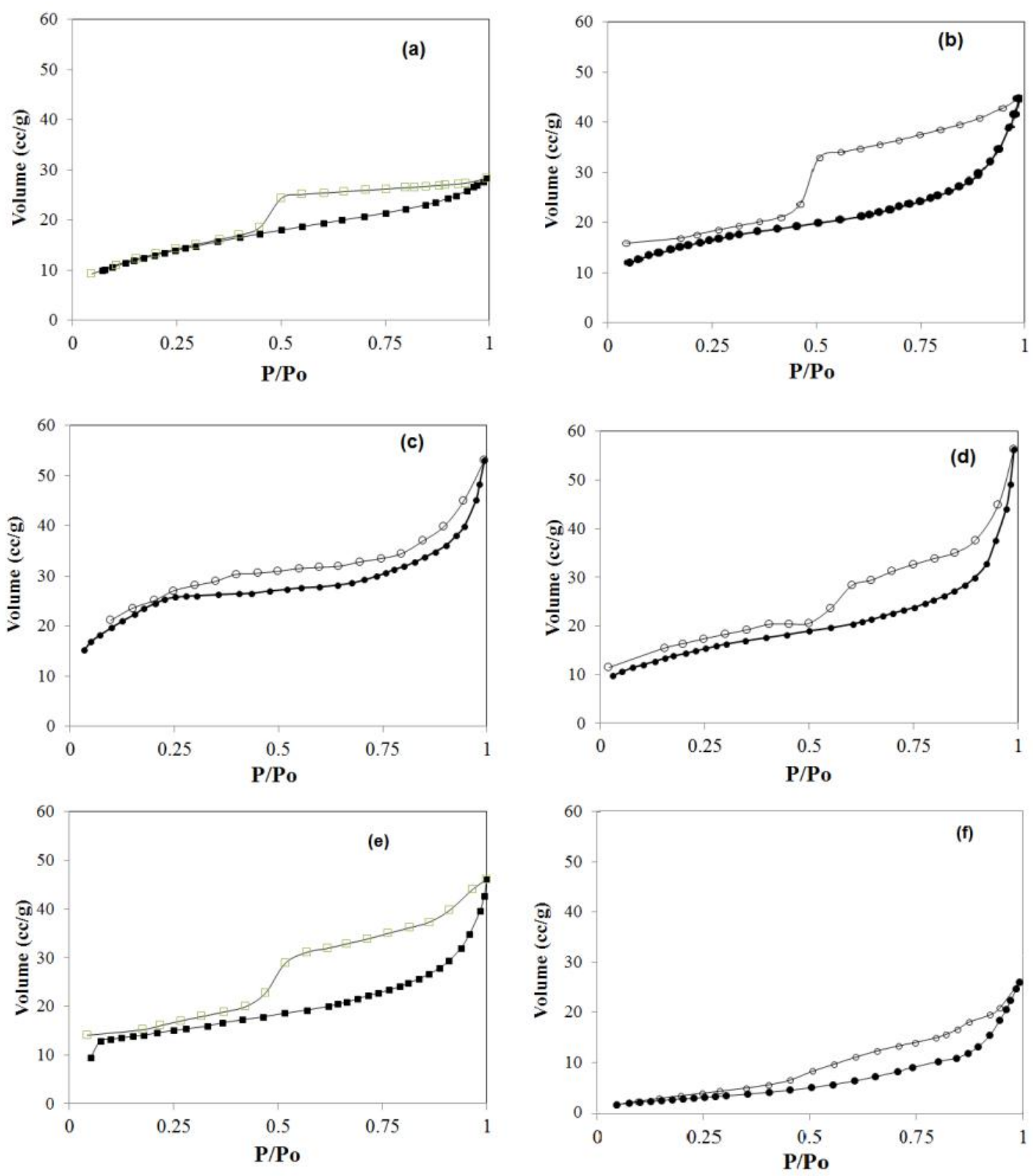

Figure 2. Adsorption-desorption pattern of (a) Bent (b) Fe/Bent-10 (c) Fe/Bent-20 (d) (b) Fe/Bent-40 
(Figure 4). A similar pattern was reported in previous studies on $\mathrm{Fe}$ pillarization, and a schematic representation of the structure is presented in Figure 5.

\subsection{Photocatalytic Study}

The abilities of prepared materials to function as catalysts in a Fenton-like phenol degradation process are presented through a kinetic curve of phenol removal during adsorption, photocatalysis and photo-Fentonlike phenol degradation in Figure 6.

The kinetic curve for phenol degradation during photocatalytic and photo-Fenton-like processes shows that the presence of both $\mathrm{Fe} /$ bents and $\mathrm{H}_{2} \mathrm{O}_{2}$ in the system accelerates the reaction. These data suggest that catalysts will accelerate $\mathrm{OH}$ radical generation from $\mathrm{H}_{2} \mathrm{O}_{2}$ cleavage under UV illumination, while,
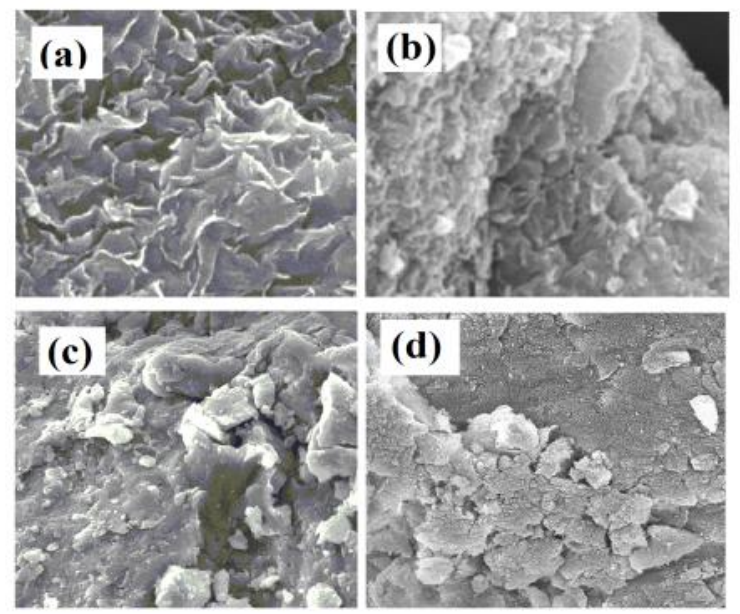

Figure 4. SEM profile of (a) Bent (b) Fe/Bent-5

(c) Fe/Bent-10 (d) Fe/Bent-20 (e) Fe/Bent-40

(f) $\mathrm{Fe} /$ Bent-60

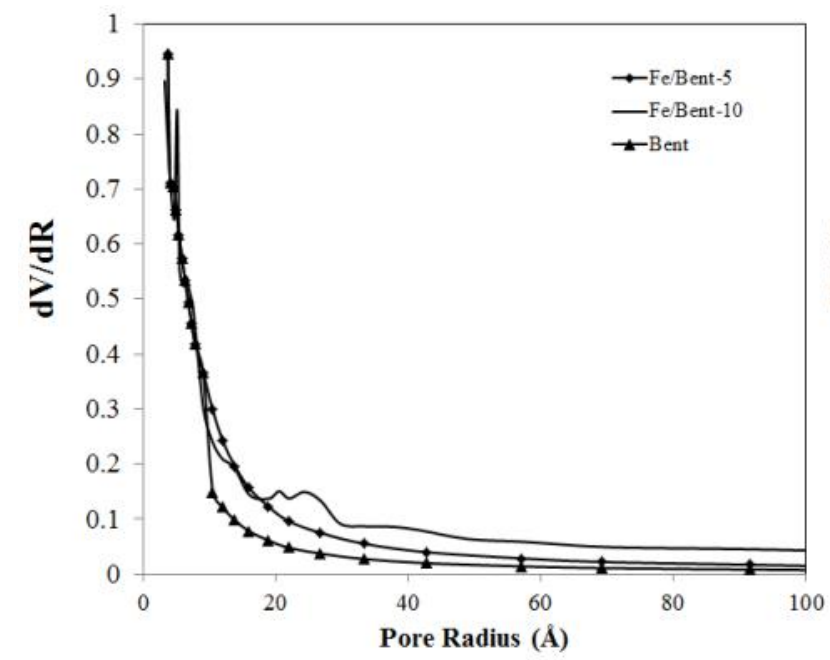

without $\mathrm{H}_{2} \mathrm{O}_{2}$, low phenol removal occurred likely because phenol degradation is caused by the $\mathrm{OH}$ produced from the solvent (water). The $\mathrm{Fe}$ content significantly contributes to photocatalytic activity because higher $\mathrm{Fe}$ content in the Fe/Bents yielded a higher phenol degradation rate due to the following mechanism:

$$
\begin{aligned}
& \mathrm{Fe}(\mathrm{III})+\mathrm{H}_{2} \mathrm{O}_{2} \rightarrow \mathrm{Fe}(\mathrm{III})\left(\mathrm{H}_{2} \mathrm{O}_{2}\right) \\
& \mathrm{Fe}(\mathrm{III})\left(\mathrm{H}_{2} \mathrm{O}_{2}\right) \rightarrow \mathrm{Fe}(\mathrm{II})+\mathrm{HO}_{2} \cdot+\mathrm{H}^{+} \\
& \mathrm{Fe}(\mathrm{II})+\mathrm{H}_{2} \mathrm{O}_{2} \rightarrow \mathrm{Fe}(\mathrm{III})+\mathrm{HO}^{\cdot}+\mathrm{HO}^{-}
\end{aligned}
$$

The Fe(III) on the Fe/Bents surface interacts with $\mathrm{H}_{2} \mathrm{O}_{2}$, and furthermore, UV light reaches photo-active sites through UV illumination; thus, the rate of organic pollutant degradation by the Fenton reaction can increase through the use of high valence iron intermediates. The Fe content in Fe-Bents was evaluated, and the photocatalytic activity indicates that Fe contributes to higher phenol removal; the phenol removal over Fe/Bent-40

Table 2. Specific surface area, pore volume and pore radius of materials

\begin{tabular}{cccc}
\hline Sample & $\begin{array}{c}\text { Specific sur- } \\
\text { face area } \\
\left(\mathrm{m}^{2} / \mathrm{g}\right)\end{array}$ & $\begin{array}{c}\text { Pore } \\
\text { Volume } \\
(\mathrm{cc} / \mathrm{g})\end{array}$ & $\begin{array}{c}\text { Pore } \\
\text { Radius } \\
(\AA)\end{array}$ \\
\hline Bentonite & 62.46 & $4.42 \times 10^{-3}$ & 14.98 \\
Fe/Bent-5 & 78.89 & $4.40 \times 10^{-3}$ & 14.67 \\
Fe/Bent-10 & 93.72 & $6.84 \times 10^{-3}$ & 15.74 \\
Fe/Bent-20 & 205.38 & $9.19 \times 10^{-3}$ & 15.83 \\
Fe/Bent-40 & 110.513 & $5.88 \times 10^{-3}$ & 9.52 \\
Fe/Bent-60 & 67.34 & $4.55 \times 10^{-3}$ & 8.89 \\
\hline
\end{tabular}

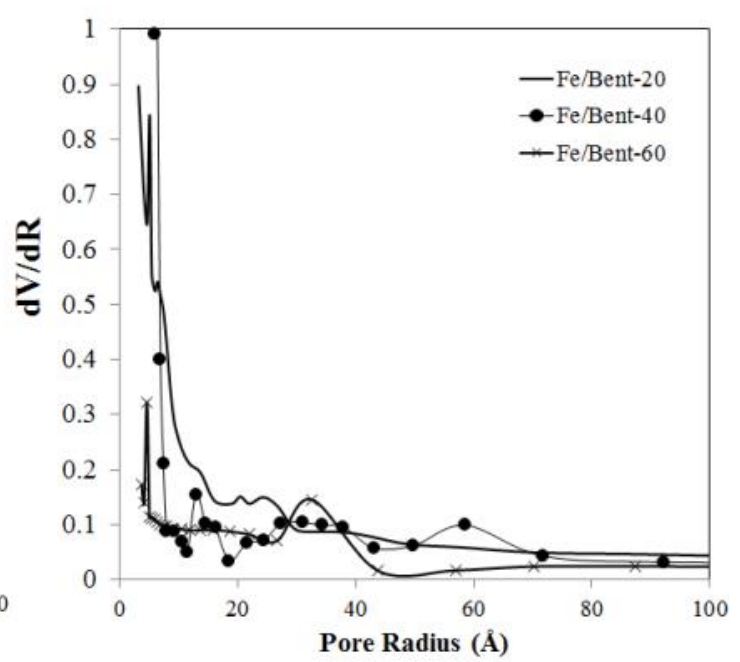

Figure 3. Pore distribution of materials 
reaches $99.67 \%$ at $240 \mathrm{~min}$ of photooxidation, while Fe/Bent-10 and Fe/Bent-20 reached 78\% and $90.00 \%$, respectively. At increasing $\mathrm{Fe}$ content, the photocatalytic activity of Fe/Bent60 is lower than that of Fe/Bent-40 for photooxidation mechanism while for Fenton and photo-Fenton the increasing Fe content is in line with the activity.

This comparison is consistent with phenol removal during photocatalysis, wherein the process occurs under similar conditions without the $\mathrm{H}_{2} \mathrm{O}_{2}$ oxidant. In order to ensure the presence of photo-Fenton and Fenton mechanism caused by leached $\mathrm{Fe}$ from the system, analysis to the leached $\mathrm{Fe}$ from Fe/Bents utilization. It is found that $\mathrm{Fe}$ leaching identified from Fe/Bent-20 and Fe/Bent-40 after the utilization at more than 1 hour with the values of $0.03-0.2 \%$ from immobilized $\mathrm{Fe}$ in both Fe/Bent-20 and Fe/Bent-40. The maximum value of leached Fe obtained from Fe/Bent-40 at 4 hours with the value of $0.048 \mathrm{ppm}(0.2 \%$ from $\mathrm{Fe}$ content in $\mathrm{Fe} /$ Bent-40) and with the same concentration of
$\mathrm{Fe}^{3+}$ added into the photo-Fenton and Fenton system there is no significant phenol degradation. The Fe(III) in the solution is responsible for the direct attacks on organic matter. By comparing the kinetics rate, the specific surface area is not primary parameter for enhancing phenol removal during adsorption processes, but also Fe content in the Fe/Bents. It is confirmed that the maxium

Figure 5. Schematic representation of (a) ideal pillared clay structure (b) house of card structure

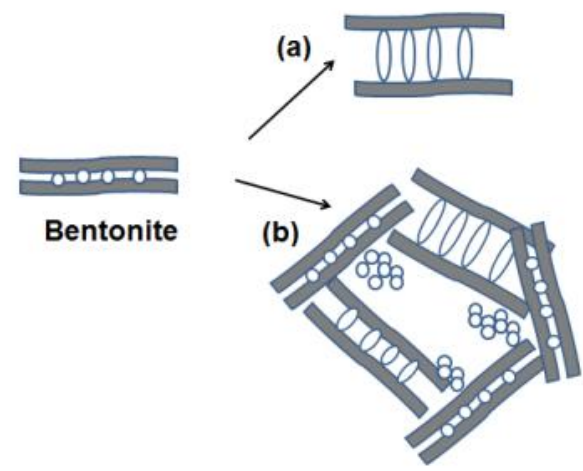

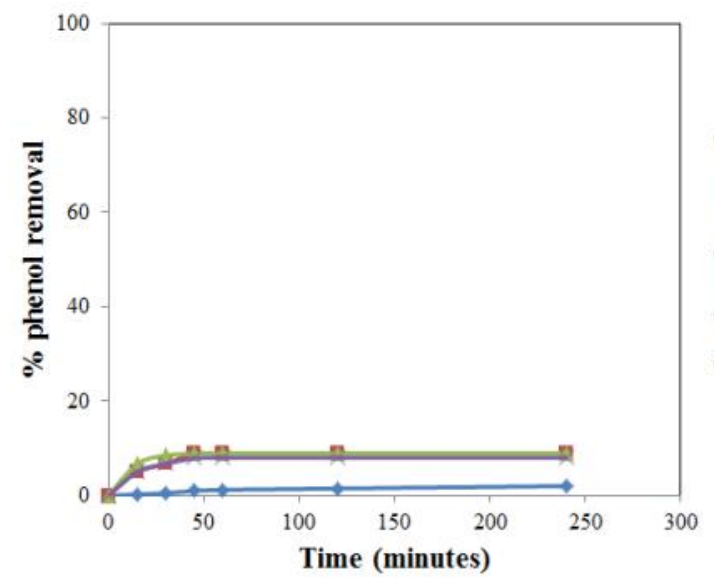
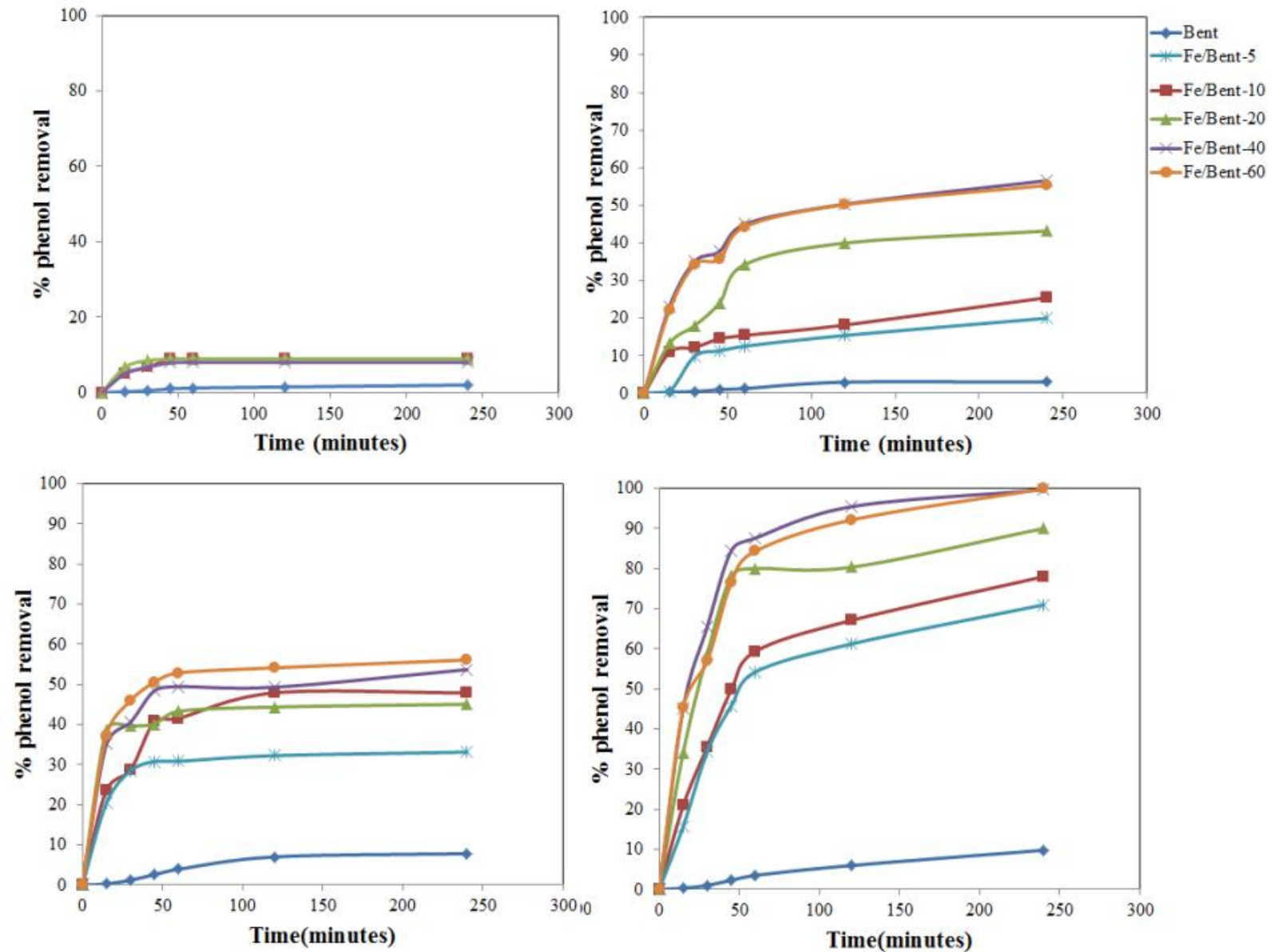

Figure 6. Kinetics of phenol removal over (a) Photocatalysis (b) Photo-Fenton like process (c) Adsorption (d) Fenton process 
photoactivity for photo-Fenton like process is gained by Fe/Bent-60.

The oxidation, not adsorption, mechanism is demonstrated by the change in chemical oxygen demand (COD) presented in Figure 7. The COD reduction trend with an increase in photooxidation and photocatalysis time over the Fe/Bents demonstrates the destruction of organic compounds during the processes. The lower COD values reflect lower organic content due to phenol destruction. The compared kinetics of COD reduction also confirmed the similar trend in photocatalytic activity in that the highest rate of $\mathrm{COD}$ reduction achieved over Fe/Bent-20 photocatalyst.

\section{Conclusions}

Iron-pillared bentonites were synthesized from Indonesian clay. A physicochemical characterization study indicates successful pillaring and incorporation of $a-\mathrm{Fe}_{2} \mathrm{O}_{3}$ phase iron oxide into a bentonite structure in which Fe affects strongly to the physicochemical character of the materials. XRD and gas sorption analysis study shows that specific surface area and $\mathrm{d}_{001}$ of the bentonite increase as increasing Fe content and reach maximum at $20 \mathrm{mmol} / \mathrm{g}$ content and furthermore at the higher content, the parameters are reducing. A photocatalytic study confirmed that all pillared bentonite materials exhibited photo-Fentonlike phenol degradation.

\section{Acknowledgement}

Authors thank to Chemistry Department, Islamic University of Indonesia for financial support by Contract No: 002//PI /2015.

\section{References}

[1] Quiroz, M.A, Bandala, E.R., Martínez-huitle, C.A. (2011) Advanced Oxidation Processes ( AOPs ) for Removal of Pesticides from Aqueous Media. Pesticides - Formulations, Effects, Fate. 686-727.

[2] Bokare, A.D., Choi, W. (2014). Review of ironfree Fenton-like systems for activating $\mathrm{H}_{2} \mathrm{O}_{2}$ in advanced oxidation processes. Journal of Hazardous Materials. 275: 121-135.

[3] Jiang, C., Pang, S., Ouyang, F., Mac, J., Jiang, J. (2010). A new insight into Fenton and Fenton-like processes for water treatment. Journal of Hazardous Materials. 174(1-3): 813-817.

[4] Pereira, M.C., Oliveira, L.C.A., Murad, E. (2012). Iron oxide catalysts: Fenton and Fenton-like reactions - a review. Clays and Clay Minerals. 47: 285-302.

[5] Matos, M.A.C., Rocha, L.L. (2015). Caffeine Oxidation in Water by Fenton and FentonLike Processes: Effects of Inorganic Anions and Ecotoxicological Evaluation on Aquatic Organisms. Journal of The Brazilian Chemical Society. 26(1): 178-184.

[6] Hashemian S. (2013). Fenton-Like Oxidation of Malachite Green Solutions. Journal of Chemistry. Article ID 809318, 7 pages.

[7] Devi, L.G., Raju, K.S.A., Rajashekhar, K.E., Kumar, S.G. (2009). Degradation mechanism of diazo dyes by photo-Fenton-like process: Influence of various reaction parameters on the degradation kinetics. Bulgarian Chemical Communications. 41(4): 385-390.

[8] Zarei, M., Khataee, A., Fathinia, M., Seyyednajafi, F., Ranjbar, H. (2012). Combination of nanophotocatalysis with electro-Fenton-like process in the removal of phenol from aqueous solution: GC analysis and response surface approach. International Journal of Industrial Chemistry. 3(1): 27-32.
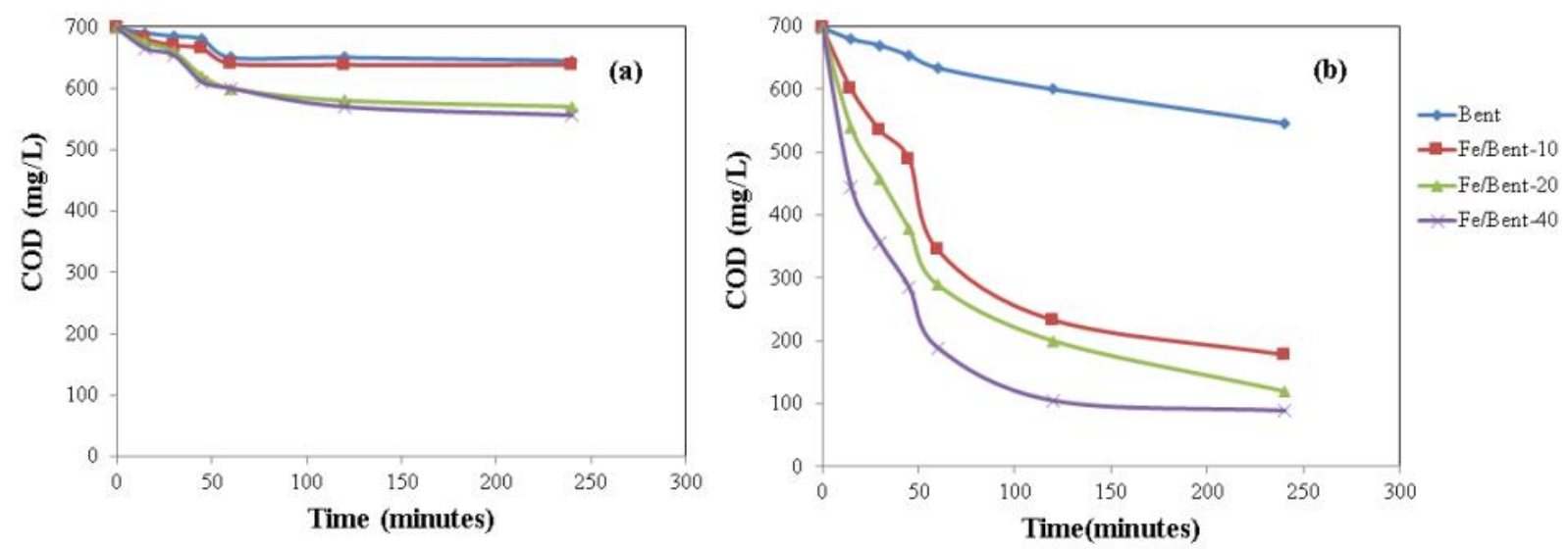

Figure 7. Kinetics of COD reduction over (a) Adsorption (b) Photo-Fenton mechanism 
[9] Yazdanbakhsh, A.R., Daraei, H., Davoodabadi, M. (2015). Degradation of phenol with using of Fenton-like Processes from water. Iranian Journal of Healt, Safety and Environment. 2(3): 325-329.

[10] Bernal, M., Romero, R., Roa, G., BarreraDíaz, C., Torres-Blancas, T., Natividad, R. (2013). Ozonation of Indigo Carmine Catalyzed with Fe-Pillared Clay. International Journal of Photoenergy. 2013: 1-7.

[11] Undabeytia, T., Galán-Jiménez, M.C., GómezPantoja. E., Vázquez, J., Casal, B., Bergaya, F, Morillo, E. (2013). Fe-pillared clay mineralbased formulations of imazaquin for reduced leaching in soil. Applied Clay Science. 80-81: 382-389.

[12] Virkutyte, J., Varma, R.S. (2014). Ecofriendly magnetic iron oxide-pillared montmorillonite for advanced catalytic degradation of dichlorophenol. ACS Sustainable Chemistry and Engineering. 2: 1545-1550.

[13] Abdennouri, M., Baâlala, M., Galadi, A., El Makhfouk, M., Bensitel, M., Nohair, K., Sadiq, M., Boussaoud, A., Barkaby, N. (2011). Photocatalytic degradation of pesticides by titanium dioxide and titanium pillared purified clays. Arabian Journal of Chemistry, Article Inpress. DOI: 10.1016/j.arabjc.2011.04.005

[14] Gil, A., Korili, S.A., Trujillano, R., Vicente, M.A.(Eds). (2010). Pillared Clays and Related Catalysts: Springer

[15] Khankhasaeva, S.T., Dambueva, D.V., Dashinamzhilova, E.T., Gil, A., Vicente, M.A., Timofeeva, M.N. (2015). Fenton degradation of sulfanilamide in the presence of $\mathrm{Al}, \mathrm{Fe}$ pillared clay: Catalytic behavior and identification of the intermediates. Journal of Hazardous Materials. 293: 21-29.
[16] Bel Hadjltaief, H., Da Costa, P., Beaunier, P., Gölvez, M.E., Ben Zina, M. (2014). Fe-clayplate as a heterogeneous catalyst in photoFenton oxidation of phenol as probe molecule for water treatment. Applied Clay Science. 91-92: 46-54.

[17] BankoviÇ, P, MilutinoviÇ-NikoliÇ A., MojoviÇ, Z., JoviÇ-JoviÇiÇ, N., ÇuniÇ, M., Dondur V., Jovanović, D.(2012). Al, Fe-pillared clays in catalyticdecolorization of aqueous tartrazine solutions. Applied Clay Science. 58: 73-78.

[18] Sahoo, S.K., Agarwal, K., Singh, K., Polke, B.G., Raha, K.C. (2010). Characterization of $\gamma$ - and $\alpha-\mathrm{Fe}_{2} \mathrm{O}_{3}$ nano powders synthesized by emulsion precipitation-calcination route and rheological behaviour of $\mathrm{a}-\mathrm{Fe}_{2} \mathrm{O}_{3}$. Science And Technology. 2(8): 118-126.

[19] Grygar, T., Hradil, D., Bezdička, P., Douŝovă, B., Capek, L., Schneeweiss, O. (2007). Fe(III)Modified Montmorillonite and Bentinite: Synthesis, Chemical and UV-VIS Spectral Characterization Arsenic Sorption, and Catalysis of Oxidative Dehydrogenation of Propane. Clays and Clay Minerals. 55(2): 165-176.

[20] Chen, J.P., Laden, H., Zang, R.T. (1995). Delaminated $\mathrm{Fe}_{2} \mathrm{O}_{3}$-Pillared Clay: Its Preparation, Characterization, and Activities for Selective Catalytic Reduction of $\mathrm{NO}$ by $\mathrm{NH}_{3}$. Journal of Catalysis. 151(1): 135-146. 